\begin{tabular}{|c|c|}
\hline & $\begin{array}{l}\text { International Journal of Trend in Scientific } \\
\text { Research and Development (IJTSRD) }\end{array}$ \\
\hline 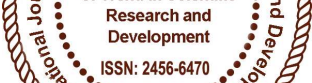 & International Open Access Journal \\
\hline 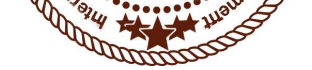 & ISSN No: 2456 - 6470 | www.ijtsrd.com | Volume - 2 | Issue - 2 \\
\hline
\end{tabular}

\title{
Direct Tension Test on Expanded Metal Mesh and Welded Square Mesh for Ferrocement Composite
}

\author{
Pallavi Sameer Parande \\ Assistant Professor, Department of Civil Engineering, \\ TSSM's Bhivrabai Sawant College of Engineering and Research, Pune, Mahashtra, India
}

\section{ABSTRACT}

Ferrocement is a special type of mortar which is usually reinforced with steel wires which can perform very well as far as crack control, impact resistance and toughnes is concern. Ferrocement has very high tensile strength to weight ratio. This project presents an experimental study on Tensile strength of different wire meshes which normally used now a days. The main objective of these experimental tests is to study the effect of using different types as well as different number of wire meshes. Test result shows that elongation of Expanded wire mesh is quite high than Welded Square Mesh.

Keywords: Ferrocement, Expanded Wire Mesh, Welded Square Mesh, Elongation, Tensile Strength

\section{INTRODUCTION}

Ferrocement is a composite material which is light in weight, at the same time strong which provides a solution to various problems in construction of different types of shapes of structures, in earthquake prone areas it is recommended due to light weight and for fast construction. In order to maintain efficient serviceability, older structures must be repaired or strengthened so that they meet the same requirements demanded of the structures built today and in future.

\section{Literature review}

Application of ferrocement has been receiving considerable attention recently, as now a days everybody is looking for cost effectiveness as well as light weight construction. Gangadharappa, Prakash, Suresh and Shesha Prakash [1] worked on Light Weight Ferrocement Subjected to Axial Tension, in which they have used Blast furnace slag with sand which is an effort towards prevention of pollution due to disposal of dangerous industrial waste. They got result as replacement of $20 \%$ of BFS has shown maximum increase in ultimate strength. Ultimate strength of specimen is found to be directly proportional to the number of mesh layers. Sayyed,

Swayambhu and Pankaj [2] referring to their observations it can be concluded that increase in tension due to increase in contact areabetween wire meshes and mortar i.e. increases in specific surface of ferrocement.

P. Paramasivam and R Sri Ravindrarajah [3] give thought on effect on Tensile strength of Ferrocement by placing bundled reinforcement near top, bottom and at midsection. They concluded that by doing such arrangement of mesh there is improvement in crack control and hence durability of ferro-structures when subjected to direct tension.

Dr. Shehab Eldin M. Mourad [4] investigated the efficiency of confining plain concrete with different layers of welded Wire Fabric or Welded Wire Mesh in order to increase load carrying capacity. In his work he found that Confinement of Plain concrete with Ferrocement jacket provides remarkable lateral 
confinement pressure which increases axial load carrying capacity.

\section{Objective of experimental study}

The main objective of these experimental tests is to study behavior of both meshes of using different numbers of wire meshes which can be further used in ferrocement composite.

\section{Experimental Work}

The experimental program includes preparing and testing of wire mesh under UTM in direct Tension. The primary variables were type and the number of layers of meshes.

\subsection{Materials used}

Cement - Cement Ordinary Portland Cement JK cement

Sand - Passing through $2.36 \mathrm{~mm}$ I.S. sieve

Water - Ordinary Drinking Water

\section{Mesh -}

a. Galvinised Welded Square Mesh of $1.6 \mathrm{~mm}$ Diameter, (20mm X 20mm) mesh opening

b. Expanded metal mesh of $1.6 \mathrm{~mm}$ width and unit weight of mesh

\section{Test Specimen -}

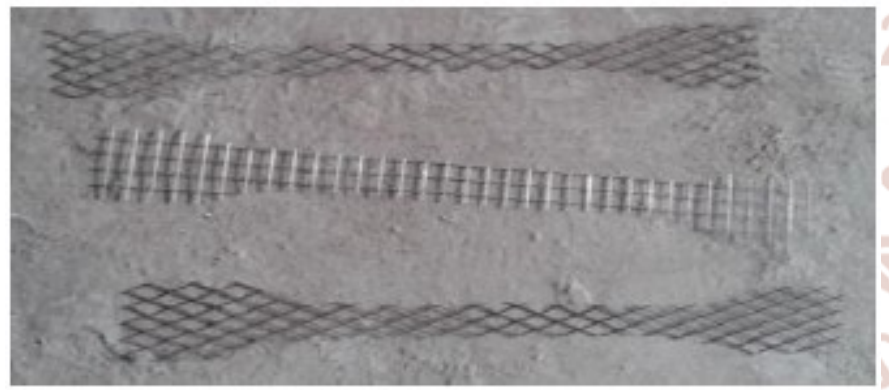

\section{Anchoring Attachment for Testing -}

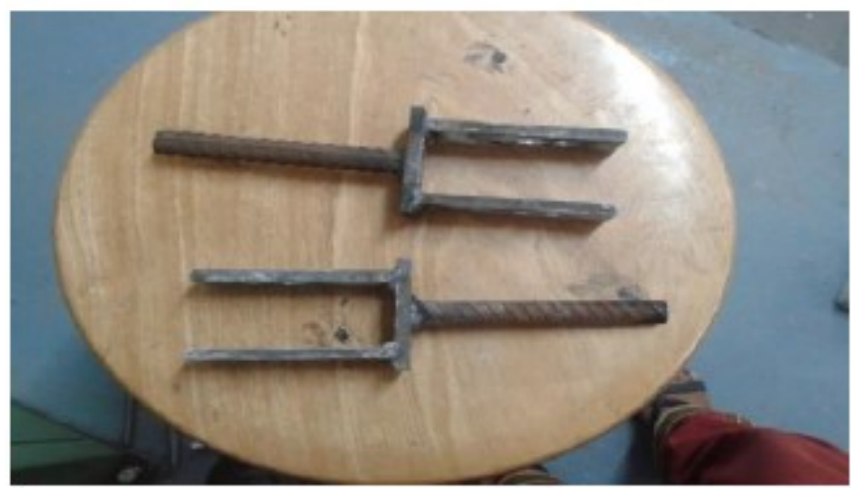

\section{Steel moulds for specimen -}

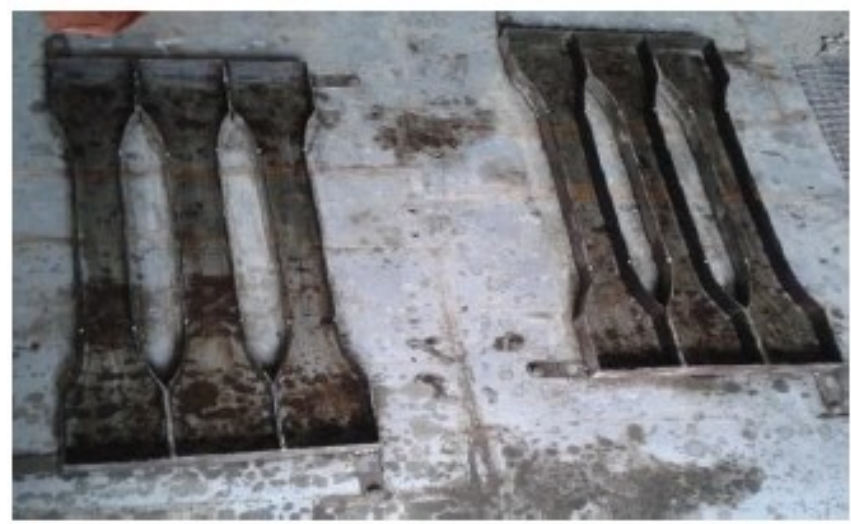

Pieces of steel pipe for fixing specimen -

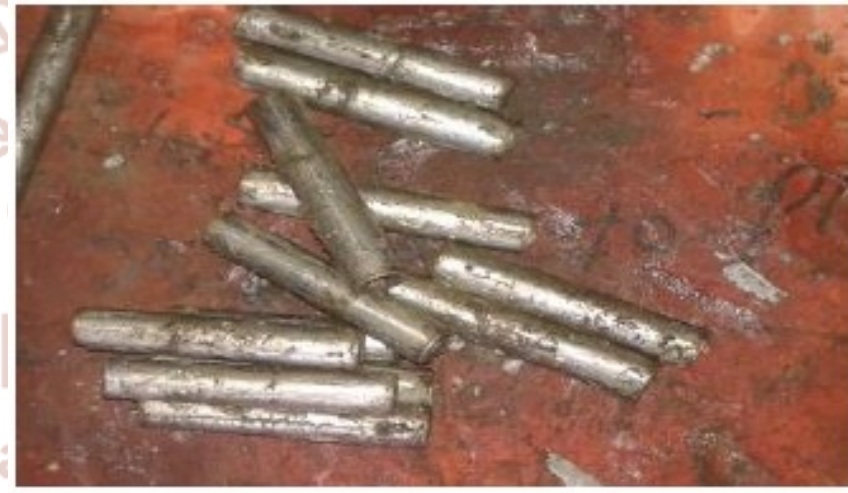

\subsection{Casting}

While casting, the mesh layers were placed in the test specimen parallel to the direction of loading with varying number of layers of mesh. The test specimen shall be prepared by embedding both ends of a rectangular coupon of mesh in mortar over a length at least equal to the width of the sample Mortar is filled only at ends for gripping of mesh. While casting 10 $\mathrm{mm}$ dia. oiled steel pipe pieces were inserted at both ends of panel for attaching grips at the time of testing. Mortar is filled only at ends for gripping of mesh. The mortar embedded ends shall serve as pads for gripping. The free or non embedded portion of the mesh shall represent the test sample

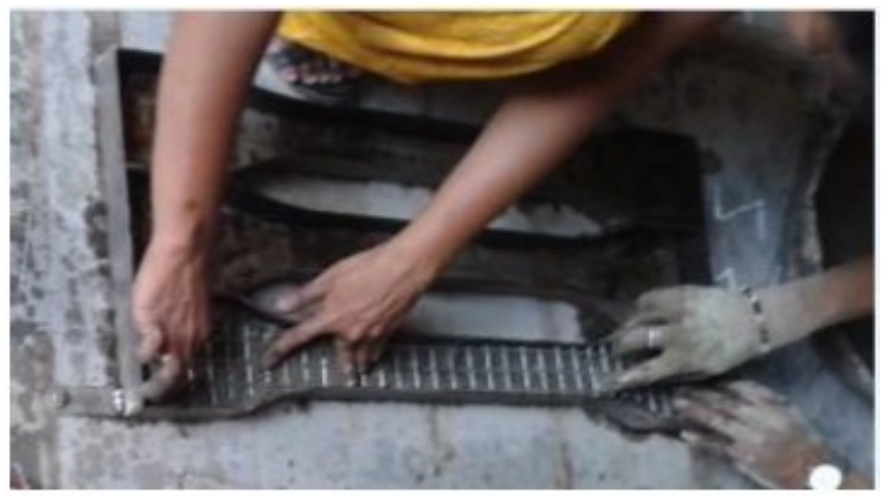

Placing mesh in the mould 


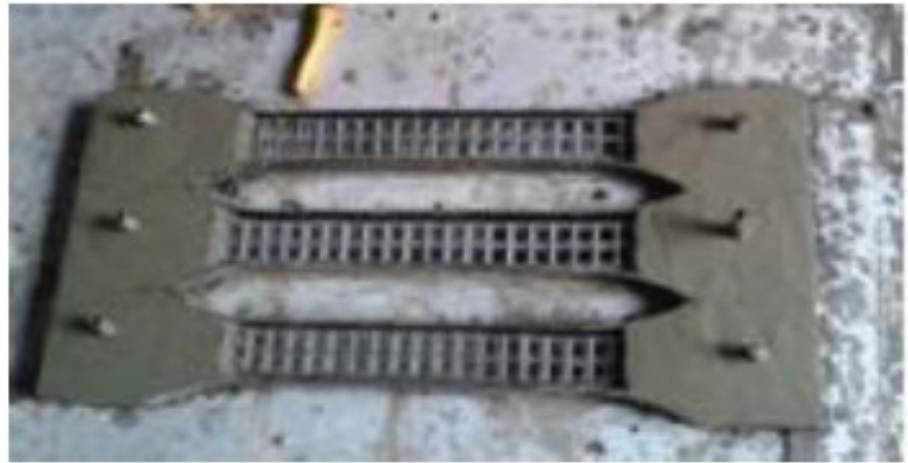

Casting of the specimen

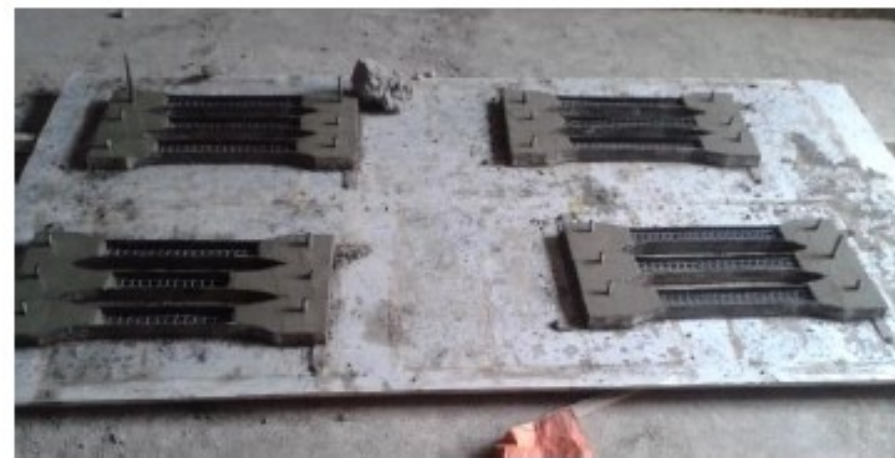

Casted specimens of both types

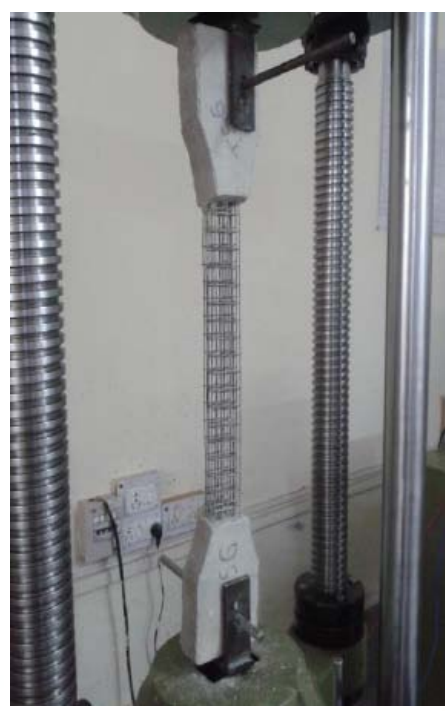

\subsection{Tested Specimen}

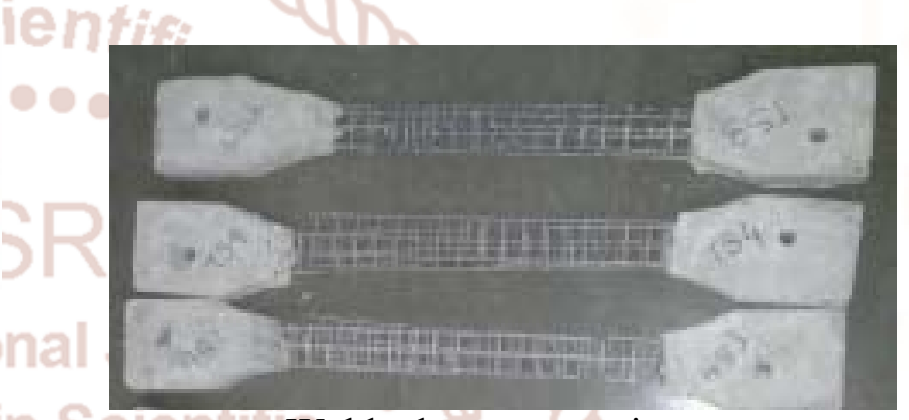

4.3 Curing

of Trend in SclenthlWeldwd square specimen

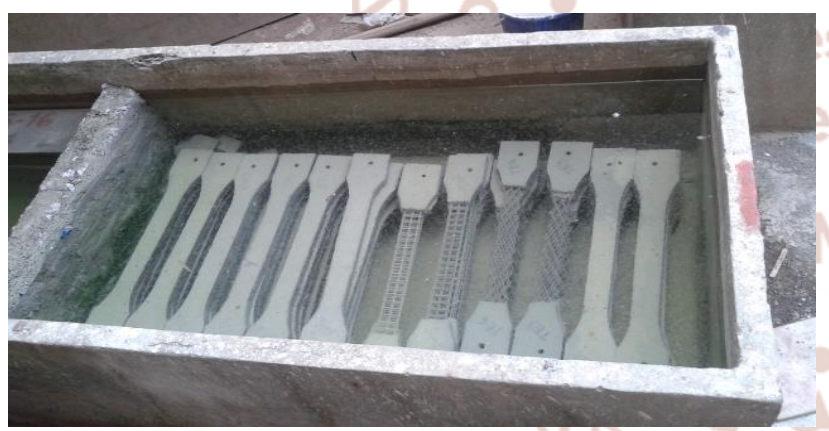

Curing of specimens

\subsection{Testing}

Direct Tension test is carried out on digital UTM of 20Ton capacity. For holding specimens special attachments were used. To hold specimen properly $10 \mathrm{~mm}$ dia bars are used to attacht specimen in UTM so that it was possible for us to apply tensile force without eccentricity. The load was applied in a direction parallel to the mesh layers. The rate of loading is kept such that test is completed in about 15 minutes. [6]

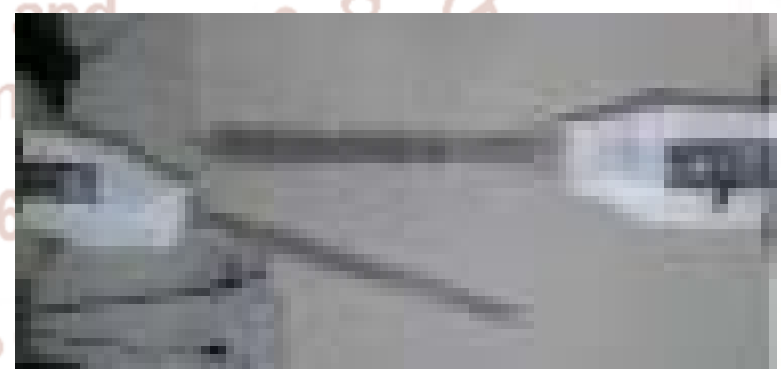

Expanded Metal Mesh specimen

\subsection{Test Results and Discussions}

For Welded Square Mesh -

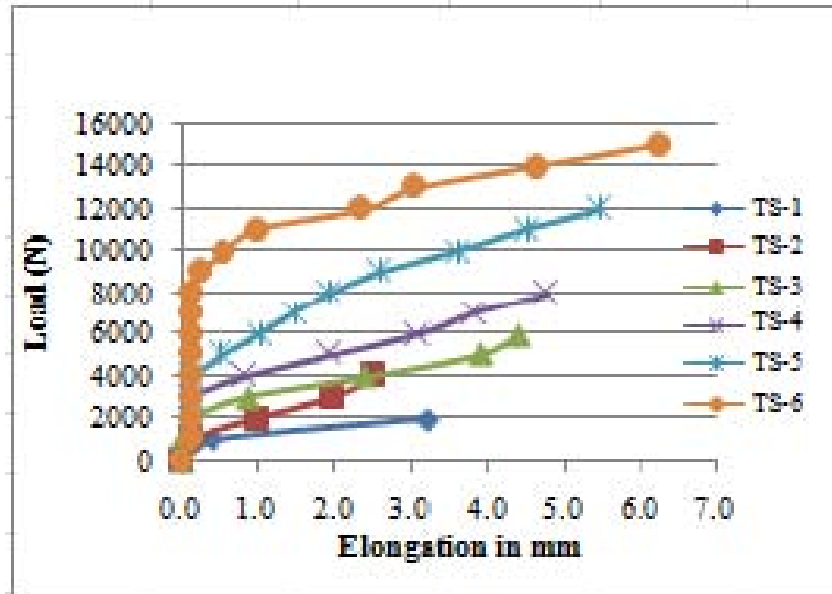

Load - Average elongation Curve 


\section{For Expanded Metal Mesh -}

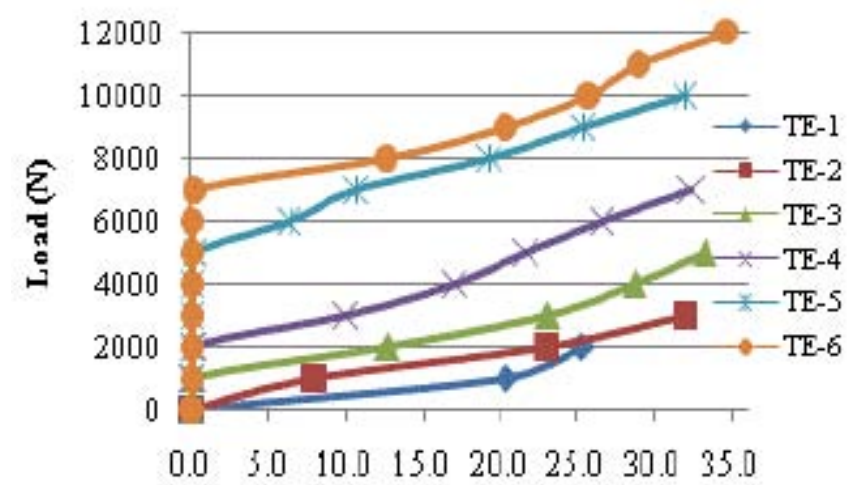

Elongationin mm

Load - Average elongation Curve

\section{Test Results and Discussion}

Ultimate tensile strength of Welded square specimen is almost double than Expanded Metal Mesh. Ultimate load carrying capacity, elongation as well as tensile strength is directly proportional to the number of mesh layers used. On other side elongation at failure also increases when volume fraction increases.

\section{REFERENCES}

1) Gangadharappa B. M. et al.," Studies on Light Weight Ferrocement Subjected to Axial Tension",International Journal of Emerging Technologies in Computational and Applied Sciences (IJETCAS), 5(3), June-August, 2013.

2) Sayyed Shoheb Navid et al., "Tensile Strength of Ferro Cement With Respect to Specific Surface" International Journal of Engineering and Advanced Technology (IJEAT), Volume 3, Issue-2, December 2013

3) P. Paramasivam et al.,"Effect of arrangement of reinforcements on mechanical properties of Ferrocement", ACI Structural journal, January February 1988

4) Dr. Shehab Eldin M. Mourad,"Performance of Plain Concrete Externally Confined with Welded Wire Fabric" Research report No. 47/426 King Saud University, college of engineering research center.

5) State of the art report on ferrocement (ACI 549R97).

6) Ferrocement and laminated cementitious composites (Antoine.E.Naaman).

7) Ferrocement Structures, Chapter 12, Bangladesh, National Building code 2012. 6-697

8) Specification for Precast and cast in situ Ferrocement, Water industry specification, UK Water fittings Byelaws scheme, No. 4-12-06, January 1990, Issue I 